Int. J. Electrochem. Sci., 14 (2019) $4903-4916$

\title{
Effect of dodecylbenzenesulphonate on Electrocatalytic Activity of NiOx Nanoparticles for glucose oxidation
}

\author{
Mohamed S. Mohamed Ahmed ${ }^{1,2 *}$, Zeinab A. Abdallah ${ }^{1,2}$, Mahmoud M. Saleh ${ }^{1,2 *}$ \\ ${ }^{1}$ Chemistry Department, College of Science, King Faisal University, Al-Hassa, KSA \\ ${ }^{2}$ Department of Chemistry, Faculty of Science, Cairo University, Giza, Egypt \\ *E-mail: mzidane@kfu.edu.sa, mahmoudsaleh90@yahoo.com
}

doi: $10.20964 / 2019.05 .16$

Received: 29 September 2018 / Accepted: 5 February 2019 / Published: 10 April 2019

The impacts of addition of organic compound (anionic surfactant) dodecylbenzenesulphonate (DBS) on the electrodeposition of nickel oxide $\left(\mathrm{NiO}_{\mathrm{x}}\right)$ nanoparticles and on the electrocatalytic oxidation of glucose from alkaline solution are studied. $\mathrm{NiO}_{\mathrm{x}}$ nanoparticles are electrodeposited on the surface of a glassy carbon (GC) electrode in the presence and absence of the DBS. Cyclic voltammetry (CV), field emission-scanning electron microscopy (SEM) and energy dispersive X-ray spectroscopy (EDX) are used for characterization of the above electrodes. The peak current of the redox couple $\mathrm{Ni}(\mathrm{II}) / \mathrm{Ni}$ (III) increases with the [DBS] before it decreases at $[\mathrm{DBS}]>1 \times 10^{-4} \mathrm{M}$. The electrocatalytic activity of the $\mathrm{NiO}_{\mathrm{x}} / \mathrm{GC}$ electrode towards the electrochemical oxidation of glucose is affected by the same manner. An attempt to correlate this electrocatalytic enhancement with the addition of the DBS is introduced. Optimum concentration of the DBS is obtained that gives the best enhancement in the electrochemical and electrocatalytic properties.

Keywords: Surfactant, Nickel, Nanoparticles, Electrocatalysis, Glucose

\section{$\underline{\text { FULL TEXT }}$}

(C) 2019 The Authors. Published by ESG (www.electrochemsci.org). This article is an open access article distributed under the terms and conditions of the Creative Commons Attribution license (http://creativecommons.org/licenses/by/4.0/). 